\title{
Path creation mechanism based on equity relationship cooperation
}

\author{
Yinliping \\ Yinliping6@hotmail.com \\ College of Business Administration, \\ Capital University of Economics and Business., \\ Zhangjiaolukou 121\# , Fengtai, 100070, Beijing ,China.
}

Keywords: path creation, equity cooperation,process

\begin{abstract}
The incumbents can leap the devastating gulf of breakthrough innovation. Based on the the existing research on complementary assets, this article presents a incumbent company Alibaba under the impact of the mobile Internet innovation, not only change the traditional business, and enter into new business areas with the help of equity cooperation. This study further expand the incumbent firm' ways of engaging in breakthrough innovation, which will help Internet enterprises to understand of path creation process better.
\end{abstract}

\section{Introduction}

When breakthrough innovation occurs, compared to the new entrants, most incumbents have obvious disadvantages to seize the breakthrough innovation opportunities, and often encounter the innovator's dilemma. But there are also some incumbent firms succeeding in path creation through new opportunity cognition and the ability change. Path creation as a process is not accomplished at one stroke, the incumbent may seize the opportunities of breakthrough innovations through the complementary assets and financial capital and other advantages, become the dominant player in the market again. However,complementary assets as a springboard of breakthrough innovation to seize the opportunity is conditional, not suitable for all breakthrough innovation. For the innovations of reconstruction of the industry value chain, the incumbent firms cannot use complementary assets advantage into the ecological system of breakthrough innovations. Our case demonstrates path creation of a China Internet technology company Alibaba with the coming of Mobile Internet. One hand, Alibaba has successfully changed the desktop Internet business to the mobile terminal.on the other hand, Alibaba by various active cooperation with mobile Internet start-ups, is carrying out all kinds of mobile Internet, innovative products and services so as to cut into the breakthrough business innovation and to regain the dominant position of the market.

\section{Literature Review}

Teece [1] think, if complementary assets is a breakthrough innovation commercialization need specialized assets, then, the ownesr of complementary assets will eventually win breakthrough innovation. Tripsas[2] shows the typewriter' commercialization, due to the advantages of complementary assets, incumbent firms were able to capture a breakthrough innovation opportunities. But if the commercialization of breakthrough innovation does not require the complementary assets owned by incumbent, the incumbents need new cooperation to get complementary assets required in path creation.. New entrants taking on the opportunity cognition advantage often can enter the market of the innovative products earlier,and has the first mover advantage. But wether new entrants can maintain the first mover advantage often depends on its cooperation with the incumbent firm. Incumbent firms often have a strong capital strength,cooperation can promote entrants' products improved quickly and speed up the commercialization process of new products. Entrants' cooperation with incumbents can a bring their brand reputation and market access. Path creation process is rarely a completely independent evolution process out of the path dependence, path creation process, often implies a certain degree 
of path dependence, the cooperation with incumbent firms can make entrants rapid variation, evolution and development based on technology and business of incumbent, the cooperation overcome the disadvantages of the lack of resources of small enterprises in the commercialization of innovation, realize their leapfrog [3]. But incumbents and new entrants into the enterprise cooperation in innovation, can still have time uncertainty, the incumbent firms can hedge their bets, maximizing the option value with minimum capital investment [4]. The cooperation is conducive to the incumbent firms overcoming the opportunity cognitive weakness, and make them abandon dominant logic of the existing business model. To learn and understand the breakthrough innovation from the new entrants point of view , can earlier prompted incumbent firm strategic transformation.

\section{Alibaba' mobile strategy based on the relationship of equity cooperation}

The strategic transformation of the traditional busines. Taobao in smart phone is an APP product that Alibaba transferred its B to C and C-C platform to mobile terminal. On surface, Taobao in smart phone is just a simple translation from Taobao of desktop.But the mobile phone Taobao already made many product innovations in the original desktop Taobao which are considerable for the mobile terminal customers to buy. Weitao is one of the change.Weitao is a button on the bottom of first page of Taobao, embedded in the mobile phone. Once the user clicks, he can receive goods information flow, provided by the different accounts. At the same time, the content generated by accounts information will reach consumers terminal,which is direct interaction between the buyers and sellers. The information flow is not only come from the merchants, also from media, experts in the field of consumption or consumer opinion, and so on. First of all, it transfer the operating right of the account to the seller. The seller makes suitable content for mobile phone. On the other hand, users are allowed to choose the information they prefer. This method give users more space, let them choose what they want to focus on. Secondly, on the bottom of Taobao's home page in mobile phone just there is a life button, which according to the user's location services, providing different service including food, buffet, film, hotel, landmark ticket, beauty, KTV etc. Moreover you can also call reservation, find map query, give feedback or call a taxi. The expansion of these services come true through investment in Gold Map wholly owned by Alibaba, Taobao's life service in mobile phones will be greatly enhanced by the navigation of Gold Map. Alibaba can use a map APP combined with the online purchases and offline purchases, provide consumers with better shopping experience to strengthen its B to C and C-C platform service level further. Thirdly, with the main entrance embedded in mobile platform, APP of Taobao in mobile phone realizes the strategic transformation from traditional business. Alibaba has purchased a $18 \%$ stake in Sina Weibo, Alibaba embedded Taobao APP in the Sina Weibo, a highly stickiness to customers platform, to make up for the problem of its low user viscosity. Through the equity cooperation relationship. By Sina Weibo, Alibaba can provied the personalized recommendation of advertising accurately according to customer information data. taobao in mobile phone make customers natural transition to mobile shopping environment. In addition, Alibaba promote social electricity business model by Weibo. With the help of word of mouth marketing, the active consumers in Weibo can drive the passive consumers i, stimulate consumers purchase desire, and then implement the buying behavior of e-commerce model.

For the traditional Alipay business on PC platform, Alibaba has carried on the bold reform, push out Alipay Wallet business. Alipay wallet is directly associated with bank card. The user can carry over fund between Bank card and Alipay account, and real-time transfers between accounts of bank card, pay back credit card, pay for gas, water and electricity fee and so on. This function transfers the functions of the traditional bank into the Alipay wallet in mobile phone. As a third-party payment platform, the expansion of Alibaba mobile payment function is very widely and deeply in the field of mobile payment. Ali Group purchase 9.9\% share of Intime business and convertible bonds at 5.37 billion Hong Kong dollars. After this strategic investment, Ali Group and Intime business will be fully open membership system, payment system, and will achieve the docking of the two business systems. On this basis, the two sides will build a foundation system to get through online and offline business, to achieve seamlessly connection between commodity 
trading online and offline, membership marketing and membership services. This system will be open to the whole society for all offline major business Group, the retail brand and retailer services. Through the acquisition, Alibaba will moves offline payment into online payments by launching a Smart phone "face pay" feature. Now Alibaba is looking the APP Alipay wallet as a distribution channel of mobile payment business, extend its payment businessto a broader range of scenarios.Now, the embedded applications are more than 60, including music payment, train ticket payment, game payment, travel payment, video payment, catering payment, group buying and so on. Users also can search and add a variety of businesses and services account to expand its mobile payment function through the wallet service button. Alibaba is change the mobile payment tool of this commercial trading activities into a users 'necessity and base in mobile service life.

The Mobile strategic of emerging business. The transformation process in mobile Internet, Alibaba not only positively change the business of the original PC end, at the same time, following the trend of mobile Internet innovation, boldly go into new areas of business to innovate. Yu Ebao is a successful case of Alibaba entering the field of Internet finance. Yu Ebao is a accounts in Alipal Wallet, similar to a bank' current deposit, customers can achieve real-time transfer between Yu Ebao account and Alipay account. In order to increase capital returns of Yu Ebao account, Alibaba acquired Tianhong funds 51\% share, Tianhong funds can give a client interest 5 times higher than traditional bank.Through equity cooperation, Alibaba have successfully transfer a lot of current deposit of traditional bank to Alipay' account.Relying on Yu Ebao, Alibaba has gone into the monetary fund field.Compared with the traditional banking, Yu Ebao has obvious advantages over attracting users deposits, Tianhong funds through Yu Ebao, manage the funds scale already rose from 10billion to 400billion yuan in half a year.[5]. Tianhong funds can be access to nearly 80milliom users of Alipay at zero cost, which brought a fund sales channel revolution. For Alibaba, the marginal cost of plusing financial products like Yu Ebao in existing payment platform is almost zero, however, this service can greatly improve the user viscosity, thus Alibaba can look Alipay wallet as the fulcrum so as to extend payment service to any field it can imagined, further improve the e-commerce ecosystem of Alibaba. Alibaba as an e-commerce platform, to provide financial services businesses is a very important service functions, Alibaba relies on his trading platform business data advantage can be more efficient than the traditional bank loan. For consumers, Yu Ebao provides the investment channels and pay channels a traditional financial system does not provide still, Yu Ebao is in favor of the marketization of interest rate. Yu Ebao is only the first step of Alibaba mobile internet financial innovation. Alibaba is planning to establish"financial Tmall" platform. Zhejiang Rongxin Hold by Ma Yun has indirectly hold the Hang Seng electronic 21\% shares,becoming its controlling shareholder. The Hang Seng electronic mainly provides software solutions to financial institutions as the IT service corporation, including banks, securities services, insurance, fund, etc. The Hang Seng electronics has won the top 100 global financial software company, they provide asset management, wealth management system, transaction management system and many other products sales in the financial field. According to the annual report of 2012, the Hang Seng electronic, provided in the fund, securities,insurance, trust management market share were 93\%, 80\%, 90\%, 75\% [6]; controlling Hang Seng electronic, Alibaba can master a great deal of financial industry data. Combined with the Ali' existing small micro financial services group, Alibaba "financial Tmall" has appeared. The intention of Ma Yun is to recreating a financial IT platform of providing financial Unified exchange after a few years. As the private banking licence opening, Alibaba is closer to Ali bank.Previously, Ali online financial services is already almost imatate banking business of the present stage. But these services are for Ali line online shopping platform, Alipay and merchant services, if the free barrier expansion to the offline people and enterprises, as well as more financial sector, Ali group must have the qualification of private banks.

In addition, Alibaba put its stretches into video website. Mobile Internet video APP is a important mobile terminal entrance. At present Alibaba announced strategically invest video site Youku Tudou. Alibaba and Yunfeng fund buy 18.5\% You-Tu shares of common stock, Alibaba holding ratio is $16.5 \%$, Yunfeng fund holding ratio is $2 \%$. You-Tu and Ali cooperation is not because of the shortage of funds, the You-Tu has hundreds of millions of dollars in cash reserves. 
However,the hundreds of millions of dollars can not realize its value. On the one hand: under the influence of Internet policy regulatory, the play scale of overseas drama is being tightening, the content You-Tu can purchase decreased sharply. Many hot overseas drama,"bankruptcy sisters", "house of cards" have been removed.According to the relevant provisions of the Culture Ministry, I'm afraid each set content that can play is only 2 minutes, which greatly damage the user experience. On the other hand, more and more TV stations began to "net"(usually in the portal and APP), at the same time, they chose to stop the content distribution to video website. The CCTV has been announced that the world cup rights this year will no longer distribution, the world cup will exclusively play by its own website and APP. Hunan satellite TV also announced that "the future of Hunan satellite TV content, will no longer distribute to video site to create Internet video platforms of their own". For the video site You-Tu future development It real needs is the quality content and the content distribution channels. Especially the video sites have layout hardware (box, TV) market today, content distribution channels is more urgent.These are precisely the field the Ali is laying recently. In the aspect of content, Ali had just invested in content producer Culture China; in content distribution channels , Ali had launched Tmall box and invested in Hasu media with the IPTV license recently. From the early Ma' personal investment in Huayi, last Ali' layout TV box, and then to this year, investment Culture China, finally to invest You-Tu, all together is more like a deliberate strategy, vertical integration online video chain of cultural industry with the Mobile Internet. Now it seems that Ali has opened the whole cultural industry chain. As for Ma, layout entertainment industry and not just to make money, more or in order to make up for their fatal lack of mobile entrance .At the same time, according Ali business thinking of "the media being entrance ,entrance is trade ", in the future putting trading into the culture industry will become a behoove thing.

Finally, Alibaba has rapidly expanded in the online travel business of mobile platform. Tourism as a few trillion market, its prospect is very broad.At present in China OTA (online travel agencies), travel perpendicular search, mobile travel APP occupy very very small market. In 2010,Alibaba launched Taobao Travel platform that the main business is air travel. Taobao Travel smartly did self localization, staggered Business travel and lead free travel to provide one-stop free platform for consumers. In Taobao and Tmall flow driven, the development of Taobao Travel is very rapid, 2011 annual turnover exceeded 10billion. While the competitor Xie Cheng' annual revenue is 3.5billion. Last year, Taobao Travel began to expand outwards, Respectively, strategic investment in mobile APP "on the road" and travel website”The poor activity" . At the same time, Ali's search products get into the field of vertical travel search. This year,Alibaba combined with Broadband Capital invest, Bai Cheng journey net, this is another online travel industry investment after the travel network" on the road “. Bai Cheng travel network make up for the lack of Alibaba online tourism products in overseas tourism. In 2013, Bai Cheng journey service outbound passengers more than 400000, year-on-year growth of $471 \%$ in 2012 , year-on-year growth of $1233 \%$ in 2011 [7]. The visa section has become a leading brand in china online travel service. With hoiding shares of these enterprises,Alibaba involved in almost all the mainstream online tourism service. Both in PC terminal, and mobile terminal, Alibaba is rapidly improving mobile online tourism layout.

\section{Conclusion}

Alibaba'path creation process is different with the former incumbent firms relying on complementary assets to get rid of the path dependence. In the transition to traditional business strategy, Alibaba did not stick to the original business model, but adapt to the trend and requirements of mobile Internet development, the original business has been actively changeded and launched again for the mobile environment, including Alipay'wallet, mobile Taobao and other products, the original business on PC end has successfully translate to mobile phone end deeply and widely. In the emerging business development, to employ opportunities produced by Mobile Intenet and the existing resource advantages, Alibaba come into many new areas, financial field, mobile video website field, mobile online travel field. Alibaba'strategic transformation is mainly with the aid of the equity cooperation pattern. The first advantage of this model is that the company do not 
assume great innovative risk, in the early of innovations it can choose some innovative firms that has great developing potential to cooperate. Second, this model can save the time cost of the transformation. Alibaba must not spend a lot of time of trial and error and market cultivation time as entrepreneurial enterprises, faster carry out its strategic transformation which is very important for Internet industry of the technology changes very fast. Third, this model can seize more potential opportunities of Mobile Internet. Fourth, Alibaba can achieve synergy effects among all businesses. But this model has obvious flaws, the first is equity partners may produce a contradictory due to different strategic development direction and fail to realize the synergy effect. For example, in the equity cooperation of "Alibaba-Sina", Sina'Micro-blog as a new social media, should be a media company with independence, but the assumption of Alibaba' social business cooperation obligation is bound to affect the public trust in the Micro-blog, which is not conducive to the development of Micro-blog. Second, for Alibaba, equity cooperation can seize new more opportunities, but also bring some problems, the more partners Alibaba group manages, the lower its management efficiency may be.

\section{Acknowledgements}

This paper has been funded by General Program projects (sm201210038009) of Beijing Municipal Education Commission.

\section{References}

[1] Teece DJ. . Profiting from technological innovation: implications for integration, collaboration,licensing and public policy. Research Policy 15(1986), p285-305.

[2] Tripsas M. . Unraveling the process of creative destruction: complementary assets and incumbent survival in the typesetter industry. Strategic Management Journal, Summer Special Issue 18(1997), p119-142.

[3] M. A. Schilling:Technological Leapfrogging:Lessons From the U.S. Video Game Console Industry,California Management Review vol 45, No 3 Spring (2003), p6-32

[4] T.Folta :. Governance and uncertainty: the trade-off between administrative control and commitment.Strategic Management Journal 19(11)(1998): 1007-1028.

[5] Chen Longhttp: the future of Yu Ebao, http://money.163.com/14/0327/16/9OBVVIKB0025335L.html

[6] http://m.baidu.com/from=1...rz7xzotkpmq706kzn9u

[7] http://www.huxiu.com/article/29667/1.html 